\title{
Implementasi Fuzzy Logic pada Penjadwalan Pengairan Irigasi (Studi Kasus : BPSDA Serayu Citanduy)
}

\author{
(Fuzzy Logic Implementation in Irrigation Water Scheduling (Case Study: BPSDA \\ Serayu Citanduy))
}

\author{
Krisna Ardhi Tama*, Maman Abdurohman, Rahmat Yasirandi \\ Departement of Informatics Engineering, Telkom University \\ Jl. Telekomunikasi No.01, Dayeuhkolot, Bandung, Jawa Barat, Indonesia \\ Email: krisnatama@student.telkomuniversity.ac.id, [abdurohman, batanganhitam]@telkomuniversity.ac.id
}

"Penulis korespondensi

\begin{abstract}
Irrigation system is an activity to get water to facilitate agricultural activities. The activity is to drain and provide water regularly to the land and then use it for land needs. This irrigation system has been implemented by BPSDA Serayu Citanduy, Central Java by using river water. Intelligent control system using Sugeno fuzzy algorithm in this study can determine the proper scheduling. The stages in the Sugeno fuzzy method are to form Fuzzy sets and then implement the implication function, the next process is Defuzzification. An intelligent control system prototype for scheduling soil irrigation using LoRa as a telemetry medium. Sugeno fuzzy algorithm application is to measure the discharge in river water and then compare it with the area of agricultural land. In this study using $\mathbf{5 0}$ hectares of land area and $38.18 \mathrm{~L} / \mathrm{sec}$ water discharge resulted in 74 minutes.
\end{abstract}

Key words: Fuzzy Sugeno Algorithm, Intelligent Control System, Irrigation System, Agriculture, Telemetry

\section{I.PENDAHULUAN}

Indonesia merupakan salah satu negara di bagian asia tenggara yang memiliki kekayaan atas sumber daya alam. Kekayaan sumber daya alam Indonesia terdiri dari berbagai sumber daya salah satunya sumber daya pertanian dan perkebunan yang tersebar secara luas di Indonesia [1]. Sektor pertanian di indonesia memiliki peranan yang cukup besar dalam perekonomian nasional, dapat dilihat dari kontribusi bidang pertanian secara tepat memposisikan pembangunan pertanian terhadap Produk Domestik Bruto (PDB), penyediaan lapangan pekerjaan dan penciptaan wirausaha, peningkatan kesejahteraan masyarakat, serta menjadi salah satu sumber perolehan devisa bagi Indonesia [2].

Pemerintah telah memposisikan sektor pertanian menjadi bagian dari prioritas utama dalam lima tahun terakhir. Pemerintah serius dalam mengoperasikan program serta kebijakan pada sektor pertanian dan terbukti dapat mendongkrak dan berkontribusi pada pertumbuhan ekonomi skala nasional. Pendapatan pada PDB Pertanian tahun 2018 telah melampaui target yang ditetapkan, membuat pemerintah Indonesia aktif meningkatkan produktifitas pada sektor pertanian. Pemerintah menerapkan gagasan pada sektor pertanian dengan mengimplementasikan teknologi dan ilmu pengetahuan ke dalam sektor pertanian diharapkan dapat lebih meningkatkan produktifitas sektor pertanian [3].

Perkembangan teknologi dan ilmu pengetahuan mengalami kemajuan pesat, salah satunya terdapat pada sistem kendali cerdas. Kemajuan tersebut membuat sistem kendali cerdas menjadi salah satu bagian terpenting dari teknologi masa depan. Saat ini, sistem kendali cerdas mampu meningkatkan kualitas serta kuantitas dalam berbagai sektor sumber daya termasuk pada sektor pertanian. Pengimplementasian sistem kendali cerdas dapat diterapkan dalam berbagai macam sistem termasuk sistem irigasi sebagai media untuk memenuhi kebutuhan air dalam pertanian.

Sistem irigasi merupakan kegiatan untuk mendapatkan air guna membantu kelancaran kegiatan pertanian. Tahapan yang dilakukan adalah dengan pembuatan sarana dan prasarana irigasi untuk mengalirkan dan menyediakan air secara teratur [4]. Sistem irigasi ini telah diterapkan oleh Balai Pengelolaan Sumber Daya Air Serayu Citanduy Jawa Tengah dengan menggunakan air sungai.

Logika fuzzy merupakan pengembangan dari logika Boolean yang hanya mengenal nilai 1 dan 0. Sementar itu logika fuzzy mengenali nilai-nilai ambang yang ada diantara kedua bilangan tersebut [5]. Menurut penelitian [6], fuzzy logic dapat digunakan untuk melakukan penjadwalan sistem irigasi untuk mengairi sawah.

Pada penelitian ini, akan digunakan sistem kendali cerdas menggunakan fuzzy logic dengan studi kasus Balai Pengelolaan Sumber Daya Air Serayu Citanduy Jawa Tengah. Air dari sungai akan diukur debit airnya lalu akan dibandingkan dengan luas lahan pertanian sehingga menghasilkan waktu penjadwalan untuk lahan pertanian. Adapun pertimbangan aspek yang diperhitungkan, yaitu: ketersediaan air, luas lahan, dan penerapan sistem irigasi dengan kendali cerdas dapat di kembangkan secara berkelanjutan (sustainable) untuk lebih efisien. 


\section{TINJAUAN PUSTAKA}

Dalam penelitian ini menggunakan metode pengumpulan data seperti observasi ke kantor BPSDA Serayu Citanduy. Selain itu juga peneliti menggunakan metode fuzzy sugeno dan menggunakan Arduino IDE, PHP sebagai metode pengembangan system.

\section{A. Logika Fuzzy}

Konsep logika fuzzy dikemukakan pada tahun 1962 yaitu metodologi sistem kontrol pemecahan masalah, yang tepat untuk diimplemetasikan dan di kembangkan pada sistem, mulai dari sistem yang sederhana hingga sistem kontrol yang rumit [7].

Konsep ini sedikit berbeda dari logika tradisional yang hanya dapat merepresentasikan sifat biner yang ditandai dengan nilai 1 atau 0 . Kedua bilangan ini merepresentasikan kondisi "ya"/"tidak" atau "benar"/"salah". Oleh karena itu konsep lama ini hanya memiliki nilai keanggotaan 0 atau 1 [8].

Operator himpunan fuzzy digunakan untuk mengkombinasi himpunan fuzzy. Berikut ini merupakan macam - macam operator himpunan fuzzy.

TABEL I. OPERATOR HIMPUNAN FUZZY

\begin{tabular}{|c|c|l|}
\hline No & Operator & \multicolumn{1}{|c|}{ Penjelasan } \\
\hline 1. & AND & $\begin{array}{l}\text { Operator irisan dalam } \\
\text { himpunan. }\end{array}$ \\
\hline 2. & OR & $\begin{array}{l}\text { Operasi gabungan pada } \\
\text { himpunan. }\end{array}$ \\
\hline 3. & NOT & $\begin{array}{l}\text { Operasi komplemen pada } \\
\text { himpunan. }\end{array}$ \\
\hline
\end{tabular}

\section{B. Logika Fuzzy Metode Sugeno}

Pada metode sugeno output sistem tidak berupa himpunan fuzzy, dapat juga berupa persamaan linear atau konstanta [9]. Metode Sugeno menggunakan singleton sebagai fungsi keanggotaan yaitu himpunan fuzzy yang fungsi keanggotaannya dapat berada di luar titik tersebut. Metode sugeno hanya memiliki 1 cara saja yaitu weight average [10]. Fuzzy metode Sugeno dapat dibedakan berdasarkan ordenya sebagai berikut :

a. Orde-Nol, memiliki bentuk persamaan

$$
\begin{gathered}
\operatorname{IF}\left(x_{1} i s A_{1}\right) \circ\left(x_{2} i s A_{2}\right) \circ\left(x_{3} i s A_{3}\right) \circ \ldots \circ \\
\left(x_{N} i s A_{N}\right) \text { THEN } \mathrm{r}=\mathrm{m}
\end{gathered}
$$

dengan $\mathrm{A}_{\mathrm{i}}$ menunjukan himpunan Fuzzy ke-i dan $\mathrm{m}$ merupakan konstanta.

b. Orde-Satu, memiliki bentuk persamaan

$$
\begin{gathered}
\operatorname{IF}\left(x_{1} i s A_{1}\right) \circ\left(x_{2} i s A_{2}\right) \circ\left(x_{3} i s A_{3}\right) \circ \ldots \circ \\
\left(x_{N} i s A_{N}\right) \text { THEN z }=p_{1} * x_{1}+\ldots+p_{N} * x_{n}+q
\end{gathered}
$$

dengan $\mathrm{A}_{\mathrm{i}}$ adalah himpunan Fuzzy ke-i dan $\mathrm{p}_{\mathrm{i}}$ dan q merupakan konstanta.

Terdapat beberapa tahapan dalam model Fuzzy sugeno sebagai berikut:

1. Penyusunan himpunan Fuzzy

Pada penyusunan himpunan fuzzy variabel input akan dikirimkan ke dalam himpunan Fuzzy untuk mendapatkan nilainilai tegas. Tahap berikutnya mendapatkan derajat dari nilai-nilai tersebut pada himpunan Fuzzy. Variabel input dimasukan pada kalkulasi nilai kebenaran dari premis pada setiap aturan.

2. Aplikasi fungsi implikasi

Tahap berikutnya implementasi fungsi implikasi yang berhubungan degnan suatu hubungan Fuzzy. Terdapat aturan yang diterapkan yang memenuhi satu fungsi implikasi. Fungsi implikasi yang digunakan pada Sugeno adalah fungsi min(minimum).

\section{c. Defuzzifikasi}

Defuzzifikasi adalah proses untuk mengkonversi setiap hasil dari inference engine yang akan dirubah menjadi suatu bilangan real. Hasil dari proses implikasi akan menjadi inputan pada proses defuzzifikasi dan output dari proses defuzzifikasi adalah sebuah nilai. Pada metode Sugeno defuzzifikasi dilakukan melalui perhitungan Weight Average (WA)

\section{Arduino IDE}

Arduino IDE (Integrated Developtment Enviroenment), merupakan sofware yang di kembangkan untuk pengembangan microkontroller Arduino. Melalui software inilah Arduino diprogram untuk melakukan fungsi-fungsi yang di perintahkan lewat sintaks pemrograman. Arduino IDE di kembangkan dengan bahasa pemrograman JAVA. Arduino IDE dilengkapi dengan library $\mathrm{C} / \mathrm{C}++$.

\section{Arduino UNO}

Arduino UNO merupakan sebuah platform yang berbasis open source yang berbentuk papan mikrokontroler yang mudah untuk digunakan. Arduino UNO memiliki 14 Pin digital Input/output yang mana 6 diantaranya bisa digunakan sebagai output PWM, 6 pin analog input, $16 \mathrm{MHz}$ quartz crystal, koneksi USB, power jack, header ICSP dan tombol reset. Arduino 
mampu support microcontroller dan dapat dikoneksikan ke komputer dengan kabel USB [12].

\section{E. Lora (Long Range)}

Lora (Long Range) adalah sebuah teknologi nirkabel low-power spread spectrum [13]. Lora diusulkan oleh Semtech pada tahun 2013. Tingkat komunikasi keseluruhan termasuk rendah karena berdasarkan pada pita frekuensi SubGHz, yang mengarah pada peningkatan masa pakai baterai dan ekspansi kapasitas jaringan. Karakteristik lain dari $L o R a$ adalah daya tembusnya, sehingga dapat mencakup area yang relatif luas, terutama di lingkungan konstruksi perkotaan yang kompleks. Berbagai fitur LoRa membuatnya ideal untuk penerapan skala besar, berbiaya rendah. Sebelum munculnya teknologi LoRa, teknologi komunikasi nirkabel jarak pendek utama adalah Bluetooth, RFID, Wifi, ZigBee, dan LoRa [14].

\section{F. $\quad$ PHP (Hypertext Processor)}

PHP adalah salah satu bahasa pemrogaman yang digunakan untuk pengembangan situs web. PHP berjalan pada sisi server sehingga dapat membuat sebuah situs web menjadi dinamis [15]. PHP memilki beberapa keunggulan,yaitu : memiliki akses yang cepat, dapat mengikuti perkembangan teknologi, memiliki akses ke berbagai database.

PHP tidak dapat dijalankan tanpa web server. PHP digunakan agar web tersebut dapat digunakan secara dinamis, seperti menambah data, merubah data, membaca data, dan menghapus data. PHP dijalankan bersamaan dengan kode HTML. PHP dapat di tuliskan dengan menerapkan langsung pada file HTML atau secara terpisah.

\section{G. $M y S Q L$}

MySQL merupakan salah satu Basis Data Management System (DBMS) yang banyak digunakan dalam pembuatan sistem informasi. Basis data ini memiliki beberapa keunggulan dibandingkan dengan DBMS lain nya yaitu: stabil, kuat, akses yang cepat, serta dapat digunakan dengan berbagai bahasa pemrograman[15].

MySQL adalah database server yang gratis yang dapat dipakai untuk berbagai keperluan tanpa harus membayar lisensi. SQL merupakan bahasa yang digunakan untuk mendapatkan data pada database yang terstruktur. MySQL dapat di akses melalui command line ataupun melalui antarmuka berupa web yang dapat mempermudah client mengakses database. Database pada MySQL dapat di berikan kata Sandi agar memberikan keamanan pada data. MySQL dapat berjalan pada berbagai platform sistem operasi seperti windows, linux, maupun mac.
PhpMyAdmin merupakan tampilan antarmuka yang berupa situs web yang terdapat pada web server. Fungsi dari PhpMyAdmin adalah mengatur database sehingga client tidak perlu menggunakan SQL untuk mengatur database dikarenakan pada client dapat melakukan nya dengan meng-klik menu fungsi yang ada pada PhpMyAdmin.

\section{H. Telemetri}

Pengukuran merupakan salah satu hal yang penting dilakukan dalam kehidupan sehari-hari, bisa pengukuran suhu, kelembapan, jarak, dan lain sebagainya. Pengukuran dilakukan dengan menggunakan alat ukur sesuai dengan spesifikasinya masingmasing. dalam pengukuran suatu objek bisa dilakukan secara langsung ataupun secra jarak jauh. Telemetri merupakan teknik pengiriman sinyal hasil pengukuran suatu objek yang dikirim secara jarak jauh dengan berbagai macam cara atau metode. Pada sistem telemetri bertujuan agar mempermudah user untuk mengambil data pengukuran dari suatu objek yang lokasinya jauh dan mengirimkan data terhadap user dalam bentuk sinyal yang selanjutnya bisa diolah menjadi data dengan teknik dan metode tertentu.

Telemetri merupakan proses pengukuran parameter suatu obyek yang hasilnya dikirimkan ke tempat yang berbeda baik dengan menggunakan kabel ataupun nirkabel. Dengan menggunakan sistem telemetri wireless, debit dapat di ukur dari tempat yang berbeda [16].

\section{Metode Penelitian}

Dalam Penelitian ini menggunakan metode pengembangan yang digunakan adalah metode flowchart, struktur logika fuzzy, dan diagram blok. Berikut merupakan flowchart penelitian ini. 


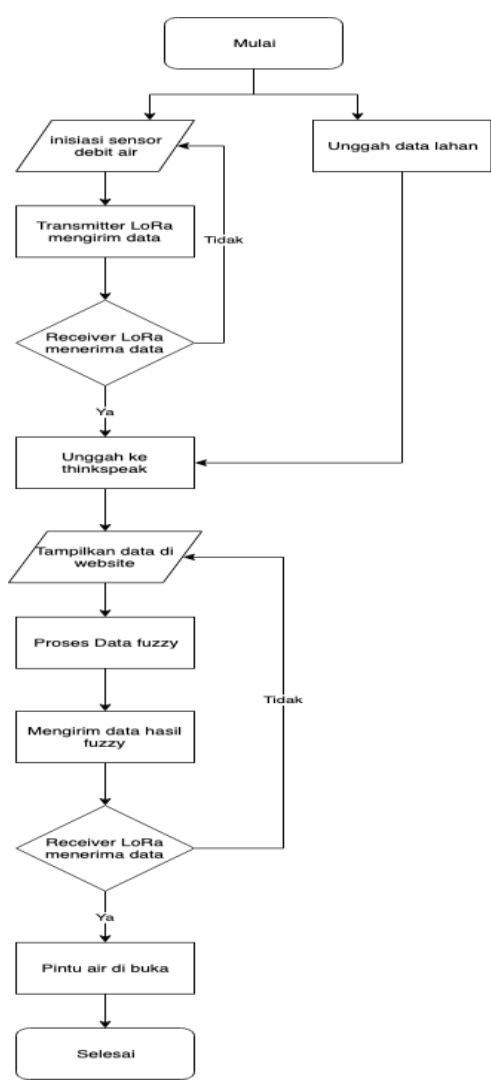

Gambar 1. Flowchart System

Pada Gambar 1 menjelaskan alur dari sistem kendali cerdas penjadwalan pengairan air irigasi pada lahan pertanian. Data dari sensor debit air akan di kirimkan melalui transmitter LoRa menuju receiver Lora apabila data di terima dengan baik maka data akan di unggah dan disimpan di database apabila data tidak di terima maka akan di lakukan inisiasi ulang. Data luas lahan di inputkan melalui website Sipel-R dan disimpan pada database. Seluruh data akan di tampilkan pada website Sipel-R dan dilakukan proses perhitungan fuzzy dengan menggunakan metode sugeno.

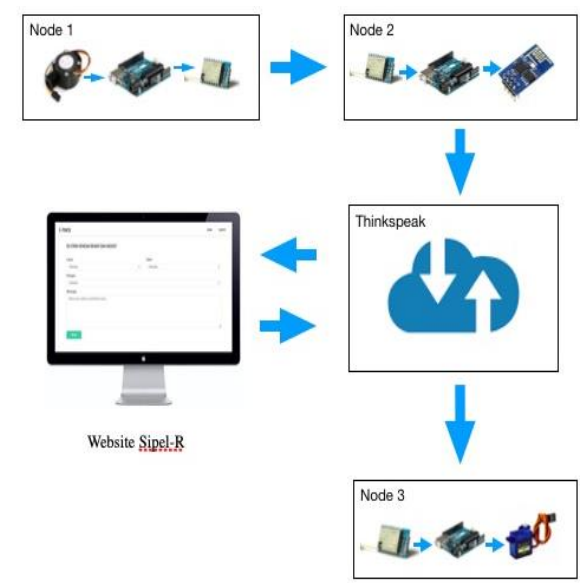

Pada Gambar 2. Debir air di ukur menggunakan sensor pengukur debit air yang dipasang pada saluran air irigasi. Luas lahan di input melalui website Sipel-R dan disimpan ke dalam database. Debit air dan luas lahan akan menjadi nilai input pada logika fuzzy untuk menentukan lama pengairan pada lahan pertanian. Data debit air dikirim dari sensor debit melalui LoRa pada node 1 ke control unit pada node 2 yang dilengkapi dengan modul LoRa dan modul wifi lalu data dikirim dan disimpan ke dalam database. Pada bagian control unit node 3 sebagai pengendali pintu air lahan irigasi di lengkapi dengan LoRa yang akan menerima data dari node 2. Modul LoRa yang digunakan adalah modul SX1728 AI-Thinker RA-01 dengan frekuensi 433mhz.

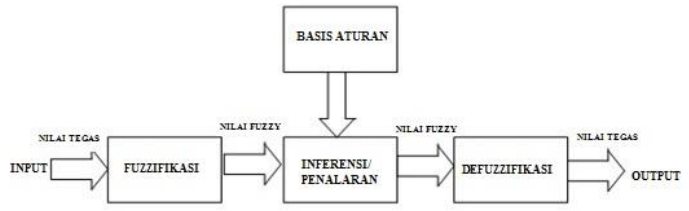

Gambar 3. Struktur Logika Fuzzy

Struktur logika fuzzy berdasarkan Gambar 3 terdiri dari fuzzifikasi yaitu proses pengambilan nilai dan dikelompokan ke dalam himpunan fuzzy tertentu. Tahap selanjutnya ialah inferensi yaitu menghitung semua data hasil fuzzyfikasi terhadap aturan yang diberikan. Tahap terakhir ialah defuzzifikasi yaitu mengkonversi hasil dari tahap inferensi menjadi sebuah nilai tegas. Setelah melewati proses perhitungan fuzzy selanjutnya adalah mengirim hasil perhitungan fuzzy tersebut kepada control unit pengendali pintu air pada lahan pertanian.

\section{HASIL DAN PEMBAHASAN}

\section{A. Website Sipel-R}

Website Sipel-R merupakan website yang digunakan BPSDA Serayu Citanduy Jawa Tengah dalam mengendalikan pintu air irigasi pada lahan pertanian. Website ini dioperasikan oleh petugas lapangan dan menggunakan algoritma fuzzy dengan metode sugeno dalam perhitungan lama waktu pembukaan pintu air irigasi pada lahan pertanian. Website ini terintegrasi dengan alat pengukur debit air pada saluran air sebagai sumber pengairan lahan. Website Sipel-R dirancang menggunakan bahasa pemrograman PHP dengan DBMS MySQL.

\section{B. Antarmuka website Sipel-R}

Gambar 2. Diagram Blok 


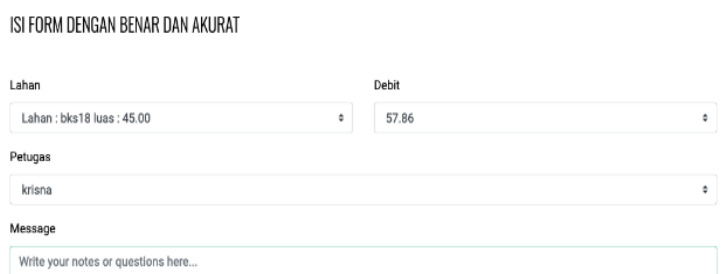

Gambar 4. Antarmuka Form Penjadwalan Irigasi

Gambar 4 merupakan tampilan antarmuka form penjadwalan irigasi. Dalam form ini terdapat dua input-an yang akan digunakan dalam perhitungan fuzzy untuk penjadwalan irigasi, yaitu: luas lahan dan debit air. Petugas melakukan input data berupa luas lahan dan debit air lalu akan diproses oleh sistem penjadwalan irigasi untuk menentukan waktu pengairan pada lahan tersebut. Data akan tersimpan di database kemudia akan diambil oleh control unit di lahan pertanian melalui jaringan internet.

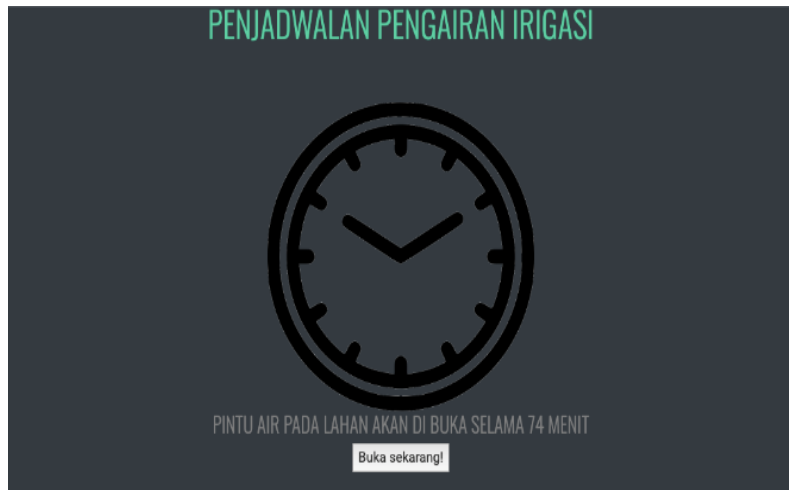

Gambar 5. Antarmuka Hasil Perhitungan Penjadwalan Irigasi Lahan

Gambar 5 merupakan tampilan antarmuka hasil perhitungan penjadwalan irigasi lahan. Pada antarmuka ini menampilkan hasil perhitungan dan terdapat sebuah tombol untuk membuka pintu air irigasi pada lahan pertanian.

\section{Identifikasi dan Fuzzyfikasi}

Tabel 2 merupakan kumpulan data yang diperoleh dari input-an luas lahan pada website Sipel-R dan debit air yang diperoleh dari sensor debit air pada saluran irigasi. Data luas lahan dan data debit air yang diberikan dimasukkan ke dalam perhitungan fuzzy logic kemudian diubah menjadi variabel linguistic menggunakan fungsi keanggotaan pada suhu, yaitu : dingin, normal, panas dan keanggotaan kelembaban, yaitu : kering.
TABEL II. Dataset luas Lahan Serta Debit Air

\begin{tabular}{|c|c|c|c|}
\hline No & Lahan & $\begin{array}{r}\text { Luas } \\
\text { lahan }\end{array}$ & $\begin{array}{c}\text { Debit air yang } \\
\text { diberikan }\end{array}$ \\
\hline 1 & Bks1 & 3.00 & 3.47 \\
\hline 2 & $\mathrm{Bks} 2$ & 6.00 & 6.94 \\
\hline 3 & $\mathrm{Bks} 3$ & 26.00 & 30.08 \\
\hline 4 & Bks4 & 4.00 & 4.63 \\
\hline 5 & Bks5 & 12.00 & 13.89 \\
\hline 6 & Bks16 & 50.00 & 57.86 \\
\hline 7 & Bks19 & 90.00 & 104.16 \\
\hline 8 & Bks20 & 33.00 & 38.18 \\
\hline 9 & Bks23 & 23.00 & 26.61 \\
\hline 10 & Bks25 & 32.00 & 37.03 \\
\hline 11 & Bks21 & 20.00 & 23.14 \\
\hline 12 & Bks12 & 29.00 & 33.56 \\
\hline 13 & CR3 & 29.00 & 33.56 \\
\hline 14 & Bks9 & 25.00 & 28.93 \\
\hline 15 & Bks17 & 39.00 & 45.13 \\
\hline 16 & Bks18 & 45.00 & 52.07 \\
\hline 17 & Bks6 & 10.00 & 11.57 \\
\hline 18 & Bks10 & 10.00 & 11.57 \\
\hline 19 & Bks11 & 10.00 & 11.57 \\
\hline 20 & Bks12 & 29.00 & 33.56 \\
\hline 21 & Bks13 & 24.00 & 27.77 \\
\hline 22 & Bks14 & 24.00 & 27.77 \\
\hline 23 & Bks15 & 21.00 & 24.30 \\
\hline
\end{tabular}

Gambar 6 merupakan gambar keanggotaan luas lahan. Luas lahan mempunyai tiga variabel linguistic yaitu : kecil, normal, dan luas. Adapun tabel keanggotaan luas lahan. Dapat dilihat pada Tabel 3.

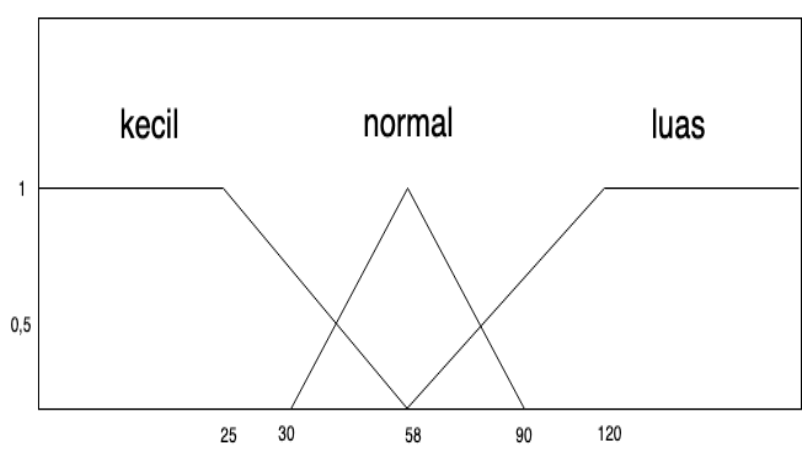

Gambar 6. Grafik Fuzzy Keanggotaan Luas Lahan 
TABEL III. Tabel KeanggotaAn Luas Lahan

\begin{tabular}{|c|c|c|}
\hline No. & Luas Lahan & Batas Nilai \\
\hline 1. & Kecil & $\mathrm{x} \leq 30 \mathrm{Ha}$ \\
\hline 2. & Normal & $30<\mathrm{x} \leq 90 \mathrm{Ha}$ \\
\hline 3. & Luas & $\mathrm{x}>90 \mathrm{Ha}$ \\
\hline
\end{tabular}

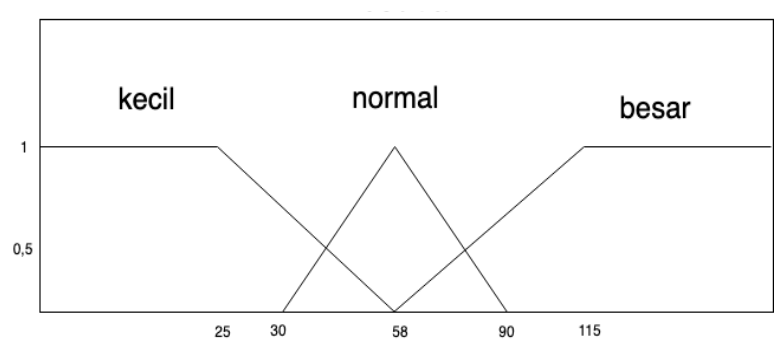

Gambar 7. Grafik Fuzzy Keanggotaan Debit Air

Gambar 7 merupakan gambar keanggotaan debit air. Debit air mempunyai tiga variabel linguistic yaitu kecil, normal, dan besar. Berikut ini merupakan table keanggotaan debit air :

TABEL IV. TABEL KeanggotaAn Debit Air

\begin{tabular}{|c|c|c|}
\hline No. & Debit Air & Batas Nilai \\
\hline 1. & Kecil & $\mathrm{y} \leq 30 \mathrm{Ha}$ \\
\hline 2. & Normal & $30<\mathrm{y} \leq 90 \mathrm{Ha}$ \\
\hline 3. & Besar & $\mathrm{y}>90 \mathrm{Ha}$ \\
\hline
\end{tabular}

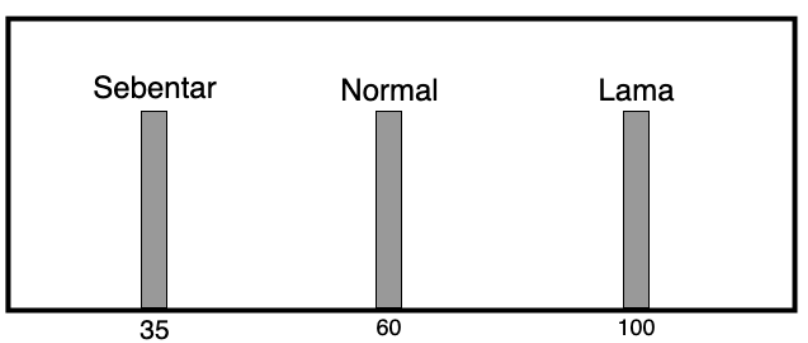

Gambar 8. Keanggotaan Lama Pengairan

Gambar 8 merupakaan gambaran keanggotaan lama pengairan. Keanggotaan lahan pengairan mempunyai tiga variabel linguistic yaitu :sebentar, normal dan lama. . Berikut ini merupakan table keanggotaan lama pengairan :

TABEL V. Tabel KeanggotaAn Lama Pengairan

\begin{tabular}{|c|c|c|}
\hline No. & Lama Pengairan & Batas Nilai \\
\hline 1. & Sebentar & $35 \mathrm{~L} / \mathrm{dtk}$ \\
\hline 2. & Normal & $60 \mathrm{~L} / \mathrm{dtk}$ \\
\hline 3. & Lama & $100 \mathrm{~L} / \mathrm{dtk}$ \\
\hline
\end{tabular}

\section{Pembentukan Aturan}

Aturan digunakan untuk pencarian atau mendapatkan kesimpulan dari identifikasi. Adapun tabel aturan untuk penjadwalan irigasi lahan dapat dilihat pada Tabel 6. Pada Tabel 6 dijelaskan aturan yang digunakan dalam perhitungan fuzzy. Operator ynag digunakan adalah AND. Aturan ini akan menentukan lama waktu pengairan berdasarkan.

TABEL VI. TABel Pembentukan Aturan

\begin{tabular}{|c|c|c|c|c|}
\hline $\begin{array}{c}\text { Rule } \\
\text { no. }\end{array}$ & $\begin{array}{c}\text { Fuzzy } \\
\text { input } \\
\text { 1 (luas } \\
\text { lahan) }\end{array}$ & $\begin{array}{c}\text { Operat } \\
\text { or }\end{array}$ & $\begin{array}{c}\text { Fuzzy } \\
\text { input 2 } \\
\text { (Debit } \\
\text { Air) }\end{array}$ & $\begin{array}{c}\text { Fuzzy } \\
\text { output } \\
\text { (lama } \\
\text { pengairan) }\end{array}$ \\
\hline 1 & kecil & AND & Kecil & Normal \\
\hline 2 & kecil & AND & normal & sebentar \\
\hline 3 & kecil & AND & Besar & sebentar \\
\hline 4 & normal & AND & kecil & lama \\
\hline 5 & normal & AND & normal & normal \\
\hline 6 & normal & AND & Besar & sebentar \\
\hline 7 & luas & AND & kecil & lama \\
\hline 8 & Luas & AND & normal & Normal \\
\hline 9 & luas & AND & Besar & sebentar \\
\hline
\end{tabular}

\section{E. Hasil Penjadwalan Waktu}

Pada penelitian ini menggunakan data luas lahan yaitu $50 \mathrm{Ha}$ dan debit air sebesar 38,18L/dtk. Data tersebut akan di proses dalam algoritma fuzzy yang akan menghasilkan sebuah nilai untuk menentukan lama waktu Pembukaan pintu air irigasi pada lahan. Untuk luas lahan $50 \mathrm{Ha}$ diterapkan rumus sebagai pada Tabel 7, sedangkan untuk debit air dengan besar 38.18L/dtk digunakan rumus pada Tabel 8.

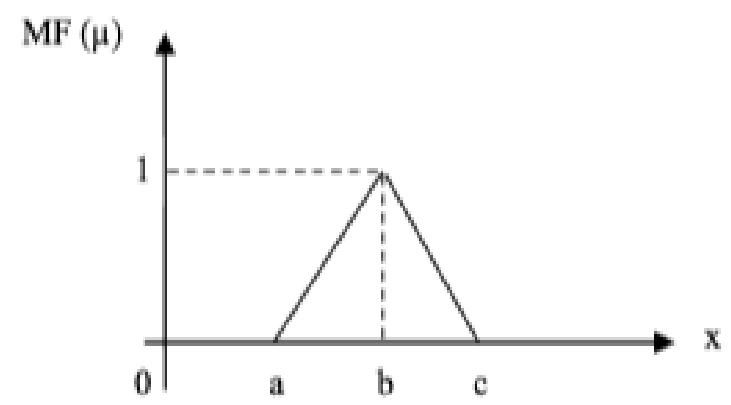

Gambar 9. Fungsi Keanggotaan Segitiga 


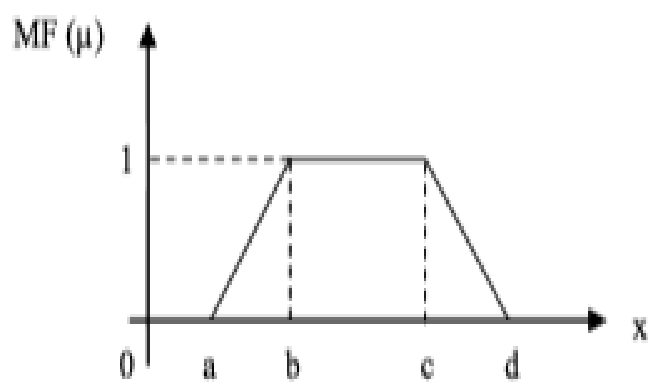

Gambar 10. Fungsi Keanggotaan Trapesium

TABEL VII. RUMUS LAHAN

\begin{tabular}{|c|c|}
\hline $\boldsymbol{\mu}$ & Rumus \\
\hline$\mu$ lahan kecil & $\frac{D-X}{D-C}$ \\
\hline$\mu$ lahan normal & $\frac{X-A}{B-A}$ \\
\hline$\mu$ lahan luas & 0 \\
\hline
\end{tabular}

TABEL VIII. RUMUS DEBIT AIR

\begin{tabular}{|c|c|}
\hline $\boldsymbol{\mu}$ & Rumus \\
\hline$\mu$ Debit kecil & $\frac{D-X}{D-C}$ \\
\hline$\mu$ Debit normal & $\frac{X-A}{B-A}$ \\
\hline$\mu$ Debit luas & 0 \\
\hline
\end{tabular}

Setelah melewati tahap fuzzifikasi proses selanjutnya adalah inferensi guna mendapat kan kesimpulan berdasar pada aturan yang diterapkan. Pada proses ini digunakan operasi logika fuzzy berupa AND dan metode implikasi MIN.

Dari hasil inferensi yang di tunjukan pada Tabel 9, lalu dilakukan proses defuzzifikasi untuk mendapatkan lama waktu pembukaan pintu air irigasi pada lahan. Pada metode Sugeno defuzzifikasi dilakukan melalui perhitungan Weight Average (WA), berikut merupakan rumus untuk melakukan defuzzifikasi.
TABEL IX. Penjadwalan Waktu

\begin{tabular}{|l|l|l|l|l|l|}
\hline $\begin{array}{c}\text { Luas lahan } \\
\text { (50) }\end{array}$ & \multicolumn{2}{c|}{$\begin{array}{c}\text { Debit air } \\
\mathbf{3 8 , 1 8 )}\end{array}$} & \multicolumn{2}{c|}{ Penjadwalan } \\
\hline Kecil & 0.2 & Kecil & 0.6 & Normal & 0.2 \\
\hline Kecil & 0.2 & Normal & 0.3 & Sebentar & 0.2 \\
\hline Kecil & 0.2 & Besar & 0 & Sebentar & 0 \\
\hline Normal & 0.7 & Kecil & 0.6 & lama & 0.6 \\
\hline Normal & 0.7 & Normal & 0.3 & Normal & 0.3 \\
\hline Normal & 0.7 & Besar & 0 & Sebentar & 0 \\
\hline Luas & 0 & Kecil & 0.6 & Lama & 0 \\
\hline Luas & 0 & Normal & 0.3 & Normal & 0 \\
\hline Luas & 0 & Besar & 0 & Sebentar & 0 \\
\hline \multicolumn{5}{|c}{$a_{1} z_{1}+a_{2} z_{2}+a_{3} z_{3}+\ldots+a_{n} z_{n}$} \\
\hline
\end{tabular}

Keterangan:

$\mathrm{WA}=($ Weighted Average $)$

$\boldsymbol{\alpha}_{\mathrm{n}}=$ Nilai predikat aturan ke-n

$\mathrm{z}_{\mathrm{n}}=$ Indeks nilai input(konstanta) ke-n

$$
\begin{gathered}
W A=\frac{0,2(60)+0.2(35)+0.6(100)+0.3(60)}{0.2+0.2+0.6+0.3} \\
W A=\frac{12+7+60+18}{1,3} \\
W A=\frac{97}{1,3} \\
W A=74
\end{gathered}
$$

Setelah melewati tahap defuzzifikasi diperoleh hasil 74 menit untuk lama pengairan lahan.

\section{HASIL DAN PEMBAHASAN}

Terdapat beberapa kesimpulan yang dapat diambil dari Penerapan Sistem kendali Otomatis Pengairan Menggunakan Metode Fuzzy Sugeno, yaitu penerapan sistem kendali otomatis pengairan menggunakan metode fuzzy sugeno dapat memberikan lama waktu pengairan untuk lahan pertanian dengan luas tertentu secara tepat. Sistem pengendalian irigasi lahan mempermudah pengaturan air pada lahan pertanian melalui jarak jauh. Dengan LoRa dapat mengirimkan data dan mengatur pintu air dengan tepat dan efisien serta jangkauan yang luas. Data luas lahan 50Ha dengan debit air sebesar 38,18L/dtk memperoleh hasil sekitar 74 menit untuk waktu lama pengairan lahan. 


\section{REFERENCES}

[1] R. F. Widyawati, "Analisis Keterkaitan Sektor Pertanian Dan Pengaruhnya Terhadap Perekonomian Indonesia (Analisis Input Ouput)," J. Econ., vol. 13, no. 1, p. 14, 2017.

[2] A. Daryanto, "MEMPOSISIKAN SECARA TEPAT PEMBANGUNAN PERTANIAN DALAM PERSPEKTIF PEMBANGUNAN NASIONAL Well Positioning Agricultural Development in The Perspective of National Development," pp. 26-46, 2012.

[3] KEMENTERIAN PERTANIAN REPUBLIK INDONESIA, "Pertumbuhan PDB Pertanian RI 2018 Melebihi Target." [Online]. Available: https://www.pertanian.go.id/home/?show=news\&act=vie w\&id=3726.

[4] Hariyanto, "Analisis Penerapan Sistem Irigasi untuk Peningkatan Hasil Pertanian di Kecamatan Cepu Kabupaten Blora," Rev. Ciwil Eng., pp. 29-34, 2018.

[5] Dr. Eng. Agus Naba, Belajar cepat Fuzzy Logic menggunakan Matlab. Andi Publisher, 2009.

[6] F. M. ILMI, "Pengembangan Sistem Kendali Irigasi Otomatis Untuk Lahan Padi Sawah Yang Rendah Emisi," pp. 1-14, 2017.

[7] Sutojo, T., Mulyanto Edy. dan Suhartono Vincent, Kecerdasan Buatan, 1st ed. Yogyakarta: Andi Offset, 2011.

[8] J. Nasir, J. Suprianto, P. Studi, T. Informatika, and U. Putera, "Analisis Fuzzy Logic Menentukan Pemilihan Motor Honda Dengan Metode Mamdani," J. Edik Inform., vol. 2, pp. 177-186, 2017.
[9] Lodewyik Rahakbauw Dorteus, "Penerapan Logika Fuzzy Metode Sugeno Berdasarkan Data Persediaan Dan Jumlah Permintaan ( Studi Kasus : Pabrik Roti Sarinda Ambon ) Application of Fuzzy Logic Method Sugeno To Determine the Total Production of Bread ," J. Ilmu Mat. dan Terap., vol. 9, pp. 121-134, 2015.

[10] G. A. W. S, Erwin Susanto, and A. S. Wibowo, "Kestabilan Sikap Kamera Berbasis Sensor IMU dengan Metode Fuzzy Logic Control The Stability of Camera Based On IMU Sensor with Fuzzy Logic Control," vol. 4, no. 2, pp. 1505$1511,2017$.

[11] L. Fausett, "Fundamentals Of Neural Network Architectures, Algorithms, and Applications," Inc.,New Jersey, vol. 116, no. 0, pp. 1-476, 2017.

[12] Y. Fazriati, "Simulasi Sistem Irigasi Otomatis Pada Tanamanam Padi Menggunakan Modul Mikrokontroler Arduino Dan Modul Gprs," pp. 1-97, 2018.

[13] A. A. and S. N. Wixted, A. J., Kinnaird P., Larijani H., Tait A., "Evaluation of LoRa and LoRaWAN for Wireless Sensor Networks," no. 1-3, pp. 35-40, 2016.

[14] K. Wang, "Application of wireless sensor network based on LoRa in city gas meter reading," Int. J. Online Eng., vol. 13, no. 12, pp. 104-115, 2017.

[15] A. Solichin S.Kom, "Pemrograman Web dengan PHP dan MySQL - Achmad Solichin - Google Buku," Univ. Budi Luhur, no. April, p. 215, 2016.

[16] A. P. S. Sugeng Harianto, Aries Buedi Setiawan, "Sistem Telemetri Pendeteksi Dini Kerusakan Air Conditioner Kendaraan Dengan Metode Scanning," Pros. SNATIF ke-4 Tahun 2017, pp. 153-160, 2017. 